Gadjah MadaInternational Journalof Business

January-April2010,Vol.12,No. 1,pp. 75-115

\title{
AN ANALYTICAL ASSESSMENT OF ASSURANCE PRACTICES IN SOCIAL ENVIRONMENTAL AND SUSTAINABLE REPORTING IN THE UNITED KINGDOM AND NORTH AMERICA
}

\author{
Annisa Melissa Manurung \\ Faculty of Economics \& Business Universitas Gadjah Mada \\ Hardo Basuki \\ Faculty of Economics \& Business Universitas Gadjah Mada
}

The objective of this study is to continue and extend previous studies in evaluating the extent to which current assurance practices promote transparency and accountability to stakeholders. This is carried out by conducting an empirical analysis of the content of assurance statements accompanying a sample of non-financial reports short-listed for the Association of Chartered Certified Accountants (ACCA) U.K. Sustainability Reporting Award and the CERES-ACCA Sustainability Reporting Award from 2006 to 2008.

The findings of this study show that several new trends in social, environmental and sustainability assurance can be observed. Firstly, accountants tend to limit their intended readership to management only and state a disclaimer for other potential readers. This diminishes the transparency and stakeholder accountability of the reporting. Secondly, there is even stronger evidence that management has the control over the scope of the assurance engagement and over what information 
gets publicly disclosed. The evidence is shown in the fact that in many assurance statements prepared by accountants, only selected parts of the reports are being assured, with no indication that it is not management who selects these parts. Finally, the recent practices of assurance engagements represented by the sample in this study have not improved the transparency and stakeholder accountability of social, environmental and sustainable reporting. Similar to the two previous studies, we assert that a generally accepted standard is needed to promote assurance statements that add meaningful values to the reliability of social, environmental and sustainability reporting.

Keywords: assurance; sustainability; transparency and accountability

\section{Introduction}

Corporate reporting on non-financial performance is not a new phenomenon. Academic studies on corporate social and environmental reporting can be traced back to the 1970 s. Furthermore, the number of companies worldwide producing stand-alone reports on their social and environmental performance has experienced stable growth since 1993 (O'Dwyer and Owen 2005). One of the most comprehensive studies of this reporting practice is the KPMG's tri-annual survey, which covers the top 250 companies of the Global Fortune 500 and the largest 100 companies in 22 countries. The latest version reveals that in 2008, 79 percent of these companies had issued such a report, which was a substantial increase from 52 percent in 2005 (KPMG 2008). Although Japanese, British and American companies are the leaders in producing non-financial reports, those in many European nations are steadily catching up (Chua et al. 2009).
A similar upward trend, albeit to a lesser extent, has been shown by the percentage of these reports that included third-party assurance. According to the same survey by KPMG, the amount rose from 30 percent in 2005 to 40 percent in 2008 (KPMG 2008). It is proposed that this is driven by stakeholders' increasing demand for credibility in reporting and the assumed association between the third-party assurance and the credibility (O'Dwyer and Owen 2005). Thus, in spite of its voluntary nature, the demand for this particular audit service is rising (Power 1991).

However, the general finding of studies on social and environmental auditing is that it has so far failed to secure public trust in non-financial corporate disclosure (Dando and Swift 2003). There is a concern about management control over the assurance process, which results in doubts concerning the success of assurance in holding corporations accountable to 
Manurung\&Basuki-AnAnalyticalAssessmentofAssurancePracticesinSocialEnvironmentalan...

their constituencies (Adams 2004; Ball et al. 2000; Belal 2002; Brorson and Park 2004; Chua et al. 2009; Dando and Swift 2003; O'Dwyer and Owen 2005; O'Dwyer and Owen 2007; Power 1991; Maltby 1995; Zadek 2004).

For instance, Adams (2004) and Belal (2002) critique that in many cases, management determines the audit's scope and design, thus effectively restricting the assuror's access to the true picture of the organization's performance. Ball et al. (2000) adds that this, combined with the fact that the assuror is often appointed by management (the agent) instead of stakeholders (the principal), means that the assuror independence from the company is questionable (2000). Furthermore, Maltby's (1995) study shows that some assurors report their findings to management or address management as the intended reader in their assurance statement. Therefore, it is foreseeable that management may only disclose audit findings that will enhance their image, instead of giving a realistic picture of the corporate performance (Maltby 1995; O'Dwyer and Owen 2007). The implication of this perceived 'managerial capture' is, of course, the lacks of credibility and transparency and doubts that assurance adds a meaningful value to social and environmental disclosure (O'Dwyer and Owen 2007; Brorson and Park 2004). In the light of these issues and the growing prevalence of non-financial reporting, the time is ripe for an analysis of the success of recent assurance practices in fulfilling their intended purposes.

\section{The Objective of the Study}

As mentioned previously, the issue addressed by this study is the lack of success of current assurance practices in enhancing the transparency and accountability of non-financial corporate disclosure. This paper aims to continue and extend those of Ball et al. (2000) and O'Dwyer and Owen (2005) in evaluating the extent to which current assurancepractices promote transparency and accountability for stakeholders. This is done by conducting an empirical analysis of the content of assurance statements accompanying a sample of non-financial reports that were short-listed for the Association of Chartered Certified Accountants (ACCA) U.K. Sustainability Reporting Award and the CERES-ACCA Sustainability Reporting Award from 2006 to 2008. Both awards are seen as the leading schemes of their kind: ACCA U.K. in the United Kingdom and CERES-ACCA in North America. Besides being the first scheme in the world, the ACCA U.K. Award has also been used as an example for later, similar awards (Ball et al. 2000). Thus, reports short-listed by these schemes can be reasonably expected to be the leaders of the reporting practice (O'Dwyer and Owen 2005), at least in the British and North American perspectives. Since this study aims at drawing conclusion on the success of 
assurance practices in enhancing the credibility of non-financial reporting, these leading examples are suitable for this study.

Similar to the study conducted by O'Dwyer and Owen in 2005, this study will use prevalent non-financial reporting and auditing standards, specifically the elements related to stakeholder accountability, as a basis for evaluating the assurance statements. These standards are those issued by AccountAbility, GlobalReporting Initiative(GRI) and Federation des Experts Comptables Europeens (FEE). The problem statement is as follows: Based on the standards set out by AccountAbility, GRI and FEE, to what extent do assurance practices in United Kingdom and North America enhance the transparency and accountability of leading non-financial corporate reporting? Underpinning this study is a concern that third-party assurance fails to promote stakeholder empowerment (Ball et al. 2000).

\section{Literature Review}

\section{Non-financial Reporting}

The term non-financial reporting in this study refers to substantial, standalone corporate disclosure on social, environmental and sustainability (hereafter, SES) performance. Environmental reporting has especially enjoyed a long history since the 1970s. Social reporting then follows, although environmental reporting remains the most common type of non-financial disclo- sure. The term of sustainability reporting, however, has caught on relatively recently (O'Dwyer and Owen 2005). Indeed, the ACCA U.K. Sustainability Reporting Award was initially called ACCA U.K. Environmental Reporting Award (emphasis added) when it was founded in 1991 (Ball et al. 2000). This initial name remained until 2001 when it was changed to ACCA U.K. Sustainability Reporting Award in order to include the broadened scope of non-financial reporting that now comprises not just environmental and social issues, but also sustainability matter (Steckel 2002).

Althoughsustainability specifically concerns 'the fair distribution of resources and opportunities between the current generation and between the present and future generations,' current sustainability disclosure does not necessarily report this (O'Dwyer and Owen 2005). Instead, this term is often used to encompass all kinds of reports on corporate efforts in complying with ethical or legal standards, albeit in the social or environmental area (O'Dwyer and Owen 2005). 'Sustainability' has thus become a catchall term for all kinds of non-financial reporting. However, the misuse of this term does not affect the data used in this study - both 'sustainability disclosure' that actually provides a report on sustainability and that which does not are suitable for this study, as long as they report the corporate efforts on social or environmental issues. 
Manurung\&Basuki-AnAnalyticalAssessmentofAssurancePracticesinSocialEnvironmentalan...

Also noteworthy is O'Dwyer and Owen's assertion that the inclusion of sustainability issues in non-financial disclosure has broadened the scope of not just non-financial accounting but also non-financial assurance (2005). It has also expanded the list of stakeholders that depend on non-financial assurance to hold companies accountable (O'Dwyer and Owen 2005). Thus, it is now even more important to evaluate the success of this assurance service in fulfilling its intended purposes.

\section{Social, Environmental and Sustainability Assurance}

SES assurance is often referred to as the third-party verification or auditing service. Individuals carrying out the service are often called assurors, verifiers or auditors. The term auditor here is potentially misleading since not all individuals performing non-financialassurance are certified public accountants. In the lack of generally accepted standards in this particular field, assurors can be environmental consultants, non-profit organizations or certified public accountants (Ball et al. 2000). This has an important implication which will be covered later in this study.

Regardless of the type of profession carrying out the assurance service, the definition of the assurance practice per se is the same. According to the International Federation of Accountants (IFAC), third-party assurance is "a process in which a practitioner expresses a conclusion designed to enhance the degree of confidence that intended users can have about the evaluation or measurement of a subject matter that is the responsibility of a party, other than the intended users or the practitioners, against criteria" (Brorson and Park 2004).

Unlike the financial auditing, the SES auditing is voluntary and does not have a framework that is commonly agreed (Belal 2002). The assurance provider can choose to follow one of the established standards or create its own set of auditing principles (Brorson and Park 2004). As such, there are also no commonly agreed key performance indicators, and assurance providers can choose from a large variety of quantitative and qualitative indicators (Brorson and Park 2004). This is in stark contrast with financial auditing, which has a set of generally accepted quantitative key performance indicators.

\section{Findings of Previous Studies}

As explained in the introduction section, previous literature in a similar strand generally finds that there is an overriding management control over the assurance process which reduces the transparency and accountability to stakeholders and renders the assurance service not credible(Adams 2004; Ball et al. 2000; Belal 2002; Brorson and Park 2004; Chua et al. 2009; Dando and Swift 2003; O'Dwyer and Owen 2005; O'Dwyer and Owen 2007; Power 1991; Maltby 1995; Zadek 2004). Maltby asserted in 1995 that 
initially, environmental audit was conducted not for external stakeholders but for management. It was a way for management to assess their own environmental performance and whether it had complied with the company's environmental policies and planning, and possibly with statutory regulations (Maltby 1995). Thus, during that time, environmental auditing was a 'managerial tool,' and its scope and process were determined by management (Maltby 1995). Existing studies on SES assurance find that these circumstances have not necessarily changed today. Since external and internal report readers need 'fundamentally different' types of corporate information, this casts doubts on the value-adding properties of the assurance service (Power 1991).

The same finding is also proposed by Ball et al. (2000) and O'Dwyer and Owen (2005), the two studies on which this paper is based. Ball et al. (2000) seek to empirically test the claim made by Power in 1991 that environmental audit has a managerialist approach that diminishes corporate transparency and stakeholder empowerment (2000). Power (1991) asserts that without generally accepted standards, the company's environmental control systems will be the focus of the audit, instead of the environmental performance per se. Ball et al. (2000) evaluate the verification statements of environmental reports short-listed for the ACCA U.K. Environmental Reporting Award, and find that Power's claim indeed has a substance (Ball et al. 2000). Their research questions as- suror independence and critiques the dominant focus on environmental management systems in the audit (Ball et al. 2000). They also find that the 'degree of rigor' applied to the assurance process is not satisfactory (Ball et al. 2000).

O'Dwyer and Owen (2005) use reporting and auditing standards set out by AccountAbility, FEE and GRI in their study. These standards contain 'key accountability-focused elements,' and the study measures the extent to which they are used in SES reports short-listed for the ACCA U.K. and European Sustainability Reporting Awards in 2002 (O'Dwyer and Owen 2005). Although this study observes a more robust approach to auditing, greater assuror independence and a greater focus on environmental performance than the findings of Ball et al. (2000), it admits that SES assurance in general still demonstrates a 'managerial turn' (O'Dwyer and Owen 2005). The lack of stakeholder engagement in the assurance process and assurors' reluctance to address specific constituencies in their assurance statements indicate such a managerial control, and the study calls for a more robust assurance standard that addresses these issues (O'Dwyer and Owen 2005).

Management control is also evident in the fact that management often appoints the assurance provider, determines the scope and design of the audit and the degree of access to internal information provided to the assurors (Adams 2004; Belal 2002). Assurors

80 
Manurung\&Basuki-AnAnalyticalAssessmentofAssurancePracticesinSocialEnvironmentalan...

thus cannot be fully independent from management. Having an assuror from the accounting profession does not necessarily guarantee independence either. Ball et al. (2000) observe that firms do not always hire accountants as the assurance provider because they would like to benefit from the degree of independence associated with the financial audit profession.

The lack of stakeholder engagement in the assurance process is another point that is criticized by studies in this field, since stakeholder engagement is especially important in setting the boundaries for an assurance process that will address all issues that are material to stakeholders (O'Dwyer and Owen 2005; O'Dwyer and Owen 2007). Without consulting stakeholders, some important issues may fail to be addressed in the assurance statement (Adams 2004). Moreover, the lack of stakeholder involvement combined with the managerial control over audit scope may result in the audit scope being defined in very narrow terms (Brorson and Park 2004). This could result in both materiality and completeness problems (Adams 2004). Indeed, O'Dwyer and Owen critique that in many cases, the approach is overly focused on merely the accuracy of data while a more holistic, broader approach similar to that applied in financial auditing would be far more desirable (2005). Completeness problem would diminish the credibility of an assurance statement in holding a firm accountable to its constituencies (Adams 2004; Dando and Swift 2003).
As such, it can be concluded that the lack of stakeholder involvement shows the low importance placed on accountability in the assurance process (O’Dwyer and Owen 2005).

Besides leading to materiality and completeness issues, a narrowly defined audit scope limits assurors in providing a high level of assurance (O'Dwyer and Owen 2005). Assurors from the accounting profession seem reluctant to provide a high level of assurance (Dando and Swift 2003). By taking a cautious approach and introducing extensive limitations to the audit scope, accountant assurors can only provide selective disclosure of the credibility of the SES report being examined (Belal 2002). O'Dwyer and Owen (2005) criticize the trend among accountant assurors to provide only a low level of assurance.

Even when stakeholder engagement is present, one should be cautious as to the extent to which management, whose power is often greater than that of stakeholders, exerts its views on stakeholders dominantly(Adams 2004). In such a case, a company could use its communications and involvement with stakeholders as a 'legitimizing tool' to justify its efforts towards accountability (Adams 2004).

Concern over assuror's reluctance to address specific stakeholder groups in assurance statements is also rampant (Ball et al. 2000; Dando and Swift 2003; O'Dwyer and Owen 2005; O'Dwyer and Owen 2007). Unlike in financial auditing, numerous SES assurance statements do not clearly men- 
tion to whom the statements are addressed, which is peculiar since SES reports most likely address a clearly stated variety of constituencies (O'Dwyer and Owen 2005).

Ball et al. (2000) and Maltby (1995) compare another aspect of SES auditing with financial auditing. Maltby points out in 1995 that since the assurance provider can come from a variety of professions and disciplines, there is no guarantee that every provider shares a set of common and standardized background knowledge to be employed in the audit process. In financial auditing, certified public accountants can be expected to bring the same know-how and experiences into the audit. However, since in SES audit this is not the case, it is important that the assuror includes a clear description of his or her competencies and prior experiences in assurance. Unfortunately, both Ball et al. (2000) and Maltby (1995) report that this is still lacking in the sample sets of their studies.

In the light of these findings, it can be concluded that assurance service does not seem to have brought about greater levels of transparency and accountability among companies reporting their SES performance. Given this concern, my key objective in this paper is to examine whether this trend still continues in British and North American contexts in recent years.

\section{Research Framework}

The framework for this study is based on three recent and high-profile assurance reporting and auditing standards that are also used in the study of O'Dwyer and Owen (2005). These standards are released by AccountAbility, GRI and FEE.

Account Ability is a non-profit think tank that aims to 'promote accountability for sustainable development' (Accountability 2003). Its framework is called the AA1000 series (AccountAbility 1999). It first published a standard for 'social and ethical accounting, editing and reporting' in 1999 (AccountAbility 1999), then issued a revised version with a separate Assurance Standard in 2003 (O'Dwyer and Owen 2005). Of the three standards employed in this study, this is perhaps the one that places the greatest importance on stakeholders (O'Dwyer and Owen 2005). Its core principles include materiality, completeness and responsiveness, while stakeholder engagement, inclusivity and completeness, continuous improvement and independent third-party verification also receive muchattention (AccountAbility 2003). O'Dwyer and Owen (2005) note that it also requires assurors to include a clear statement of their competencies, independence from the auditee and impartiality towards stakeholders. Due to all of these stakeholder-focused elements, the same authors predict that AA1000 is the most challenging standard of all three to follow, for both preparers and auditors of the SES reports (O'Dwyer and Owen 2005).

FEE (Federation des Experts Comptables Europeens), a representa- 
Manurung\&Basuki-AnAnalyticalAssessmentofAssurancePractices inSocialEnvironmentalan...

tive of the European accounting profession, issued a Discussion Paper titled 'Providing Assuranceon Sustainability Reports' (FEE 2002). It exhibits an approach that is more cautious than AA1000 in order to prevent an 'expectation gap' between the users' expec- tation of the level of assurance provided and the true level of assurance (FEE 2002). Its emphasis on stakeholders is less than that of AA1000, although it does aim to guide assurors wanting to provide a high level of assurance (O'Dwyer and Owen 2007).

Figure 1. Recommended Minimum Contents of Assurance Statements Based on AA1000, FEE and GRI.

\begin{tabular}{|l|l|l|l|}
\hline ContentofReport & \multicolumn{1}{|l|}{ AA1000 GEE } & \multicolumn{1}{|l|}{ GRI } \\
\hline Title & & & \\
\hline Addressee & & & \\
\hline Name and location of assuror & & & \\
\hline Scope and objective of the engagement & & & \\
\hline Respective responsibilities of reporter and assuror & & & \\
\hline Competencies of assuror & & & \\
\hline Independence of assuror from reporting organization & & & \\
\hline Criteria used to assess evidence and reach conclusion & & & \\
\hline Assurance standards used & & & \\
\hline Extent of stakeholder participation in the assurance process & & & \\
\hline Impartiality ofassurortowards stakeholders & & & \\
\hline Conclusion/opinion: & & & \\
\hline Materiality(from a stakeholderperspective) & & & \\
\hline Completeness & & & \\
\hline Responsiveness to stakeholders & & & \\
\hline Performance & & & \\
\hline Reporting on reservations/qualifications & & & \\
\hline Additional commentary: & & & \\
\hline Progress in reporting and assurance since last report & & & \\
\hline $\begin{array}{l}\text { Suggestions for improvements ininteresting reporting and } \\
\text { processes }\end{array}$ & & & \\
\hline The report date & & & \\
\hline
\end{tabular}

Source: O’Dwyer and Owen (2005) 
Gadjah Mada InternationalJournal of Business, January-April 2010,Vol. 12,No. 1

Although it shares similarities with the standard issued by the Global Reporting Initiative (GRI), GRI is more demanding on the assurance provider concerning a number of issues: (1) the requirement of a clear statement about the independence of assuror, (2) the extent of stakeholder engagement in the assurance process (and any limitation in it), and (3) the requirement that the conclusion of the assurance should deal with the SEA report's 'accuracy, completeness and reliability' (O'Dwyer and Owen 2007). GRI, whose standard is called the Sustainability Reporting Guidelines, is a non-profit organization purporting to develop sustainability reporting guidelines that can be applied and accepted worldwide (GRI 2002). It is also known for involving multiple stakeholders across different fields and disciplines in developing its guidelines (O'Dwyer and Owen 2005). Unfortunately, although it does put an emphasis on stakeholder engagement in the assurance process, it does little to explain as to how this should be carried out (O’Dwyer and Owen 2005).

Figure 1 is adapted from O'Dwyer and Owen (2005). It lists the possible contents of assurance statements, and indicates whether these are required by each standard (O'Dwyer and Owen 2005). A grey-shaded box indicates that it is required while a black one indicates that it may be included but is not a requirement. As can be inferred from the Figure 1, AA1000 is the most 'demanding' of all three.

\section{Methodology}

\section{Research Design}

This paper employs an empirical, content analysis of assurance statements accompanying a series of SES reports deemed to be leading 'bestpractice' reports due to their shortlistings for the ACCA U.K. and CERES-ACCA Sustainability Reporting Awards. The statements will be judged against the accountability-focused elements of the standards explained above. The analysis is comprised of locating each statement in each report, reading it, looking for the recommended minimum contents laid out in the table above, analyzing the extent to which they are applied and how clearly they are explained in the statement, and looking for similar findings and trends spotted by previous literature to see whether these continue to bepresent in the current sample. This study also look at the Judges' Reports, which are reports made by the judging committee of the ACCA U.K. Sustainability Reporting Award. Besides listing out the SES reports short-listed for that year's award, the Judges' Reports also give a general opinion of the quality of that year's SES reports and the areas that need improvements. As it can be quite critical, the commentary in these reports is also valuable in this analysis. Finally, a content analysis will be guided by a set of key questions that will be elaborated on later in this study.

84 
Manurung\&Basuki-AnAnalyticalAssessmentofAssurancePracticesinSocialEnvironmentalan...

This method is chosen as it is the method used in the two studies from which this paper stems, and also in other research in a similar strand. The publicly released assurance statements are also the only sources available for analyzing the assurance of SES reports, unless in-depth case studies involving interviews with auditors performing real life SES assurance are conducted. Although such studies would provide more insights into the assurance process, it is not foreseeable to conduct such research given the limited opportunities and resources to do so. Hence, the content analysis is the only available way of conducting this study.

The author fully accepts that such an approach has limitations. As explained in the first section of this paper, such an approach is inherently subjective. However, with thoroughness and care in carrying out the analysis, we contend that there are still values in such an analysis, and it can still provide a valuable starting point in understanding the current SES assurance service. For example, the studies by Ball et al. (2000) and O'Dwyer and Owen (2005) employ the same research method and are often used and cited by other similar studies in this field.

\section{Data Collection Method}

Data used in this study are acquired from the ACCA U.K. and CERES-ACCA Sustainability Reporting Awards during the period of 20062008. In their websites, ACCA U.K. and CERES-ACCA publish the awards' Judges' Reports for each year, and each lists out the SES reports short-listed for that year's awards. We then go to the website of each company whose report was short-listed, and retrieve the report, usually from the report or download archives. Although it is highly unusual that the report is not available on the website, in some occasions where that is the case, we could retrieve it from the sustainability report online databases such as Corporate Register (http:// www.corporate-register.com), Global Reporting (http://www.globalreport ing.org) and EnviroReporting (http:// www.enviro-reporting.com). These can be accessed by the general public. If the report is assured by a third-party verifier, the assurance statement is normally included in the report or made available on the company's website. It is these assurance statements that finally comprise the data used in this study.

This sample is chosen for the following reasons. First, ACCA U.K. and CERES-ACCA are two of the largest SES reporting award schemes in the world. ACCA U.K. is the first of its kind and has been used as an example by later schemes. It is therefore contended that the SES reports short-listed by these awards can be expected to exhibit 'best practices,' and could thus show us the extent to which leading SES reports in the world promote transparency and accountability. Second, although the two studies on which this paper is based only use the ACCA U.K. Sustainability Reporting Award, 
this paper also uses the CERES-ACCA award in order to expand the scope of the previous studies. As already mentioned by the research of Chua et al. (2009), United Kingdom, United States and Japan are currently the most 'heavily represented' countries in the field of SES reporting. Including the CERES-ACCA award in this study allows the results to better reflect this fact, since ACCA U.K. is for companies in the United Kingdom whereas CERES-ACCA is for those in North America. Japan is not included in this study due to time constraint and the possibility of a language barrier. Third, since this research aims to continue those of Ball et al. (2000) and O'Dwyer and Owen (2005), the data used must be more current than those used in their studies. As such, the period of 20062008 is chosen. Instead of O'Dwyer and Owen (2005), who use data from one year only, this study employs data from three years.

\section{Data Analysis Method}

The analysis is guided by four things: (1) the list of recommended minimum contents in the table adapted from O'Dwyer and Owen (2005), (2) the findings and trends spotted by previous studies cited in the literature review, (3) the Judges' Reports of the ACCA U.K. Sustainability Reporting Award which include commentary on the quality of the reports and their shortcomings, and (4) a series of key questions. Each assurance statement in the data is read and analyzed based on these four criteria. In order to mini- mize errors and omissions while reading the assurance statements, each statement is checked at least three times (at different times and by different reseachers) against each criterion. Similar to the studies of Ball et al. (2000) and O'Dwyer and Owen (2005), the different approaches or presentations of accountant assurors and environmental consultant assurors, if any, are noted and analyzed. Any variations are compared to those spotted in the previous studies.

The key questions guiding this study are a combination of those guiding Ball et al. (2000) and O'Dwyer and Owen (2005). Hence, they are more comprehensive than the questions posed in this study (see Appendix C).

\section{Results and Discussion}

The sample used in this study comprises assurance statements accompanying the SES reports short-listed for the ACCA U.K. and CERESACCA Sustainability Reporting Awards from 2006 to 2008 . There are 59 reports in total. 50 reports, or 85 percent of the sample size, were assured by a third-party. This is a significant increase from the percentages in the studies of Ball et al. (2000) and O'Dwyer and Owen's study (2005), which were 60 percent and 59 percent, respectively. Two inferences can be made from this fact: (1) the trend to use an assurance provider among SES reporters is still rising and (2) as noted by Ball et al. (2000), higher-quality reporting seems to go hand in hand with the 
Manurung\&Basuki-AnAnalyticalAssessmentofAssurancePracticesinSocialEnvironmentalan...

third-party assurance. These 50 assurance statements make up the final sample in this study.

The studies in 2000 and 2005 made a distinction between assurance statements prepared by certified public accountants and those by consultants. Consultants may include a wide range of occupations, and in this study they are environmental consultancy companies, verification companies and even individuals with experiences in the SES reporting field. The reason for this distinction is that they find distinctively different approaches taken by the two professions in their assurance engagements. In general, accountants seem to favor a cautious approach that prohibits them from providing a high level of assurance, whereas consultants are more likely to focus on the valueadding measures of completeness, fairness and overall balance of the SES reporting (Ball et al. 2000; O'Dwyer and Owen 2005). This study utilizes the same distinction in the observation of results.
Table 1 shows how the 50 sample reports are divided into those prepared by consultants and those by accountants. It also compares these percentages with those observed in O'Dwyer and Owen's study in 2005.

In the study conducted by O'Dwyer and Owen, assurance statements by accountants made up a slightly larger proportion than those by consultants. In this study, this situation is clearly overturned, with consultants making up a significantly higher percentage. Although this observation cannot immediately be extended to the world of SES reporting and assurance in general, this may be the trend spotted among better-quality reports. One suggested cause for this is accountants' general reluctance to provide a high level of assurance, which is arguably more meaningful and promising for stakeholders. This general reluctance will soon be seen from the results of this study. The results are arranged based on the questions listed in the Data Analysis Method sub-section.

Table 1. Types of Assurance Providers for Sample Analyzed

\begin{tabular}{lcccc}
\hline & \multicolumn{2}{c}{ Current Study (2009) } & & O'Dwyer and Owen (2005) \\
\cline { 2 - 3 } Consultant & 31 reports & $62 \%$ & & $46 \%$ \\
Accountant & 19 reports & $38 \%$ & & $54 \%$ \\
Total & $\mathbf{5 0}$ reports & & $\mathbf{1 0 0 \%}$ & \\
\hline
\end{tabular}




\section{Information on Assurance Providers}

This study is interested in certain information about the assurance providers, namely information on the assuror's salary, the assuror's and SES report preparer's responsibilities, and the assuror's competencies, backgrounds and past experiences. Each information provides an insight into the extent to which assurance statements can add value to SES reports.

No accountant assuror mentions in the statement the fee he or she receives for performing the tasks. This is in stark contrast to financial auditing, where the fee level is always declared in order to give further information to the readers about the company-auditor relationship, including the assuror independence from the company. Four consultant assurors or 13 percent of the whole consultant sample give an indication of fee level. This is one example of the more informative approaches taken by consultants in general. Although miniscule, it is already an improvement from the sample sets observed by Ball et al. (2000) and O'Dwyer and Owen (2005), where no assuror mentioned their fee levels.

Similar to the observation in O'Dwyer and Owen (2005), accountants are more likely than consultants to provide clear information on the responsibilities of the assurors and the reporting company in an assurance engagement. In this study, all accountants provide such information, compared to only 31 percent by consult- ants. Perhaps this can be explained by the fact that accountants are accustomed to stating the responsibilities of parties involved when conducting a financial audit. This type of information is important for the report readers to understand further the relationship between the assuror and the reporting company. It can give an insight into the assuror independence from the company and how stakeholder-centered an assurance statement is.

For example, PricewaterhouseCoopers' assurance statement for Anglo American's Report to Society 2007 states that the company's directors' responsibilities include "thepreparation and presentation of the identified selected KPIs in accordance with internal corporate policies and procedures," while PricewaterhouseCoopers is obliged to "express to the directors an opinion on the selected KPIs." From this description of responsibilities, several things can be inferred:

- The assurance statement is limited to "selected KPIs," instead of the whole report. According to AA1000 AS, one of the assurance standards used in this study, an assurance statement must be stakeholder-centered for it to be value-adding to stakeholders. If the assurance statement only attests to certain parts of the report while ignoring the rest, it may not be fully value-adding to stakeholders who may be interested in other parts of the report.

- The wording of the responsibilities does not suggest that the KPIs are 


\section{Manurung\&Basuki-AnAnalyticalAssessmentofAssurancePracticesinSocialEnvironmentalan...}

selected by the assuror. Usually, when the assuror determines the scope of the assurance, this is mentioned clearly in the assurance statement. The unclear wording may suggest that the KPIs are selected by the company directors, in which case the assurance scope is then determined by the company. In other words, instead of the assuror analyzing the report based on the stakeholder concerns, the assuror is doing so predicated upon the managerial interest or perspective. This can further diminish the value added by the assurance to the report.

- It is mentioned that the directors must prepare the KPIs "in accordance with internal corporate policies and procedures." Thus, instead of preparing them with the stakeholder concerns in mind, which is what the AA1000 AS requires, the directors are to ensure that the KPIs are in accordance with company policies only. This has an adverse impact on the value of the assurance statement for the stakeholders.

- Since the assuror is obliged to express an opinion "to the directors," it can be inferred that the intended reader of the assurance statement is the company management rather than the stakeholders. An assurance statement created with the stakeholders in mind and that created for the corporate management will definitely have a different direction and provide different values for the stakeholders.
As can be seen from the points above, a clear description of the responsibilities of assuror and the company can provide a useful insight into the extent to which the assurance statement can promote transparency and stakeholder accountability. This is why it is important to have these responsibilities spelled out in details. Those who do describe the responsibilities of involved parties generally mention that the company must prepare and provide the SES report or selected parts of it, and that the assuror must attest to the provided information. Two of the consultants who do not provide this information only mention the responsibilities of the company, which gives an incomplete picture of the assuror-company relationship. These results substantiate those of O'Dwyer and Owen in 2005. In this study, all but one accountant mention the responsibilities of parties involved, while consultants in general mention the responsibilities of only one of the parties.

Information on the assuror's competencies gives the readers an idea of the assuror's capability of carrying out his or her tasks. As mentioned in previously, there has yet to be generally accepted standards governing the field of SES assurance. This means, unlike financial auditing, that there is neither a standard of the qualifications required for an assuror nor the type of occupation qualified to be an assuror. As a result, a variety of occupations may perform an SES assurance, bringing different sets of knowledge, skills and competencies into the field. Since it is 
inevitable that these skills and competencies vary in depth and quality, the resulting work may also vary in quality. Thus, an assuror's competencies should be of great interest to the report readers. Clear information on the competencies may allow readers to infer the quality of the assurance.

O'Dwyer and Owen (2005) note that the Big Four accountants seem to rely on their company names to imply that they are capable of carrying out the assurance work responsibly and effectively. This paper observes the same phenomenon. None of the accountants in the sample clearly states his or her competencies and in sufficient details. For instance, the accountants from Ernst and Young mention in their assurance for BHP Billiton's 2007 Sustainability Report that "our team has acquired competencies and experiences for this engagement" without specifying what competencies and experiences they refer to. PricewaterhouseCoopers and Deloitte and Touche even do not mention anything remotely related to competencies in their assurance statements. Similarly, consultants from Lloyd's Register Quality Assurance's verification for BT's 2008 Sustainability Report mentions that their team is "multidisciplinary" and that it has gone through "a rigorous appraisal of qualifications and experiences." From a stakeholder's point of view, when assertions such as these are not supported by more details, they seem to add little value.

However, in general, consultants are more likely to provide greater de- tails in this regard than accountants. SGS U.K., in providing assurance for GlaxoSmithKline's 2006 Corporate Responsibility report, states that the company is experienced in "management systems and service certification; environmental, social and ethical auditing and training; environmental, social and sustainability report assurance." Six other reports or a total of 23 percent of the consultant sample describe their competencies along these lines. This is a decline from 48 percent observed by O'Dwyer and Owen (2005).

When it comes to information on backgrounds and past experiences, however, accountants seem to be catching up with consultants. The percentage of consultants disclosing their relevant backgrounds and past experiences is still high (54\%), similar to the O'Dwyer and Owen's (2005) study, where the percentage was also close to half $(48 \%)$. However, the percentage of accountants disclosing this type of information has increased from 11 percent to 56 percent. For example, Ernst and Young mentions in their assurance statement for BHP Billiton's 2007 Sustainability Report that "our team includes specialists from the global environmental and sustainability networks, which undertake similar engagements with a number of Australian and internationalbusinesses." Similar tones have been employed by the other consultants in the sample who also disclose this type of information. Although the percentage of disclosing accountants and consultants are nearly 
Manurung\&Basuki-AnAnalyticalAssessmentofAssurancePracticesinSocialEnvironmentalan...

the same, consultants are more likely to declare the number of years in which they have been providing the assurance service for a particular company.

\section{Information on Intended Readership}

Clear information on the intended users of an assurance statement gives an insight into the focus of the statement. An assurance statement which is clearly addressed to stakeholders can at least be expected to discuss and/ or prioritize stakeholder concerns. This is the type of assurance that will enhance an SES report's transparency and accountability, and thus its value to stakeholders.

O'Dwyer and Owen (2005) find that assurors often do not mention the intended constituencies in details (only $27 \%$ ) or mention stakeholders that are not the same as those addressed by the SES reports. This is different from financial auditing, where both the financial and the audit reports are intended for the same sets of users.

In this research, a new trend is observed. Interestingly, and indeed alarmingly, no report mentions specific stakeholder groups. All accountants address management as the only intended user of the assurance statement, and present a disclaimer for other potential users. A typical example is shown by Ernst and Young's assurance for British American Tobacco's 2002 Sustainability Report (see Appendix D1).
This is alarming since eliminating stakeholders as parties who can benefit from the assurance statement immediately diminishes the transparency and stakeholder accountability of the assurance statement. It also raises doubts about the value of the assurance to stakeholders, since an assurance intended only for management may not cover all stakeholder concerns. It is apparent that explicitly limiting the intended readership to management and proclaiming a disclaimer concerning other users are meant to limit accountants' responsibility. This is in line with the generally cautious approach of accountants to performing SES assurance engagements. It also suggests that management may have a control over the assurance scope and methods, and over what information gets publicly disclosed. This managerial turn is suggested by both Ball et al. (2000) and O'Dwyer and Owen (2005), who fear that in such cases, assurance engagement may only be "an added bonus, spun off from a management exercise."

When it comes to consultants, similar to the findings of Ball et al. (2000) and O'Dwyer and Owen (2005), they generally do not mention the intended readership at all, simply using the terms "stakeholders" or "readers" in their statements. One consultant states a disclaimer for users other than management. This approach of not addressing any specific stakeholder also raises doubts as to whether the assur- 
ance statements are intended to address all matters material to stakeholders.

\section{Information on Assuror Independence}

Assuror independence, is extremely crucial for the transparency and accountability of a report. This research is interested in three things: (1) if the assuror makes a reference to independence, (2) if the assuror has relationships other than the assurance engagement with the company which may compromise the independence, and (3) if the assuror recognizes any consequence of less-than-full independence in the assurance engagement.

In this study, 80 percent of assurors refer to their independence from the reporting company, which is a significant increase from the 46 percent observed by O'Dwyer and Owen (2005). The same study observes that accountants seem to be satisfied with simply stating that they are independent from management without providing further details. Although 100 percent of accountants do state their independence, this research shows that most of them $(84 \%)$ also state that they comply with the International Standards for Assurance Engagements 3000 (ISAE 3000) issued by the International Auditing and Assurance Standards Board (IAASB), which requires them to be independent from management. A high percentage $(89 \%)$ also explains that they do not have any other engagement with the management which can compromise their independence and objec- tivity. For instance, it can be seen in Appendix D2 (the Ernst and Young's statements in their assurance for British Petroleum's 2007 Sustainability Report). Similar to O'Dwyer and Owen in 2005, this paper also observes that it can be easily inferred from the description of responsibilities provided by accountants that they are indeed independent from management.

On the other hand, only 68 percent of consultants clearly state their independence. The other 31 percent simply do not refer to independence at all. Of those 68 percent or 21 out of 31 reports, two may be the cases of "dissociated consultancy" discussed by Ball et al. (2000) (Appendix D3). In 2007, the consultant indeed made suggestions of amendments which were all followed by the preparer (Appendix D4). Thus, the consultant was basically verifying his or her own suggestions. In the other case, individual assurors for Shell in 2007 also participated in reviewing and commenting on chosen topics to be covered in Shell's SES report, the report outline and content, and the first drafts. This may compromise the objectivity of the assurors. These two statements (Appendices D3 and D4) are the only ones that should recognize, in their statements, the consequences of less-than-full independence from management. However, no such recognition could be inferred or seen from their assurance statements. Nonetheless, similar to the findings of O'Dwyer and Owen (2005), less-than-full independence is far from common among SES assurors. Both the percentages of 
Manurung\&Basuki-AnAnalyticalAssessmentofAssurancePracticesinSocialEnvironmentalan...

accountants and consultants making a reference to independence have also increased since Ball et al. (2000), and O'Dwyer and Owen (2005).

\section{Information on Assurance Processes and Methods}

Clear information on the assurance scope, standards and criteria is important in analyzing the extent to which assurance promotes report transparency and stakeholder accountability. All but one assuror describe the engagement scope, and 50 percent clearly and specifically mention the aspects of the report that are not assessed, a rise from 37 percent found in O'Dwyer and Owen's (2005) study. For example, URS Verification states in their assurance statement for Xstrata's 2006 Sustainability Report that the assurance scope only includes four elements of the report, namely safety, health, environment and community. Ernst and Young, in their assessment of British American Tobacco's 2007 Sustainability Report, also specifies that "The scope of our work was limited to activities at headquarters. We did not visit any of the operating companies." Consultants $(82 \%)$ are more likely than accountants $(18 \%)$ to state what their engagement scope has left out.

All but one assuror mention the standards and criteria used in analyzing the SES report. AA1000 Assurance Standard is by far the most commonly used, with 96 percent claiming to focus on the standard's materiality, completeness and responsiveness principles. The Global Reporting Initiative's G3 guidelines are a close second. This is a clear improvement from the percentage of assurors making a reference to a specific standard, which are 27 percent in Ball et al. (2000) and 29 percent in O'Dwyer and Owen (2005). This is perhaps due to the increasing emphases on materiality, completeness and responsiveness issues raised by several latest standards, especially the AA1000 Assurance Standard.

\section{Table 2. Types of Work Undertaken During Assurance Process}

\begin{tabular}{|c|c|c|c|}
\hline $\begin{array}{l}\text { Percentage of assurors } \\
\text { conducting... }\end{array}$ & $\begin{array}{l}\text { Current } \\
\text { Study }\end{array}$ & $\begin{array}{l}\text { O'Dwyer \& } \\
\text { Owen (2005) }\end{array}$ & $\begin{array}{c}\text { Ball et al } \\
(2000)\end{array}$ \\
\hline Data review and validation & $86 \%$ & $93 \%$ & $70 \%$ \\
\hline Systems and processes review & $64 \%$ & $85 \%$ & $43 \%$ \\
\hline Site visits & $64 \%$ & $56 \%$ & $32 \%$ \\
\hline Stakeholder interview & $5 \%$ & $10 \%$ & NA \\
\hline Stakeholder engagement & $5 \%$ & NA & NA \\
\hline
\end{tabular}


Only 23 percent of assurors do not make a clear description of work undertaken in the assurance process. Consultants (31\%) are more likely than accountants $(11 \%)$ not to provide this information. Table 2 presents the percentage of assurors performing certain types of work during their engagement, compared to the percentages from the two previous studies where available. When the information is not available in the previous study, it is marked as NA.

In general, although O'Dwyer and Owen observe "a discernible improvement in the extent of work undertaken by assurors" when they compare their results to those of Ball et al. (2000), a general feeling of improvement is not seen from the results of this study. For example, although data review and validation seems like the most obvious task that needs to be carried out in an assurance engagement, only 86 percent of assurors make a clear reference to this (Appendix D5).

Even less percentage of assurors (64\%) claim to have carried out the systems and processes review. This is an important type of review where the management control systems and processes which are in place for creating the SES report are examined. There is a slight increase of assurors undertaking site visits (from $56 \%$ in 2005 to $64 \%$ ), but the extent of stakeholder interview and engagement, which is heeded as crucial by the AA1000 Assurance Standard, remains negligible. Although assurors attempt to provide information on stakeholder involvement in the assurance process, the wording of the information is generally very broad and vague. Crucial details are often left out. As an example, Lloyd's Register Quality Assurance's assessment of BT's 2008 Sustainability Report states that LRQA conducted their own "independent analysis of stakeholder issues" but does not provide further information as to how this was done and whether stakeholders were involved in the independent analysis. The assurors of British Petroleum's 2007 Sustainability Report state that "our stakeholder engagement activities were limited to attendance in two events." However, no detail is given about what the events were, why those events were chosen as their stakeholder engagement activities, what the assurors did during the events and how they involved the stakeholders. As such, report readers have no way of judging whether the stakeholder engagement activities are sufficient to ensure that material stakeholder concerns have been considered and included in the report.

This is precisely the problem; without sufficient information on the extent of work undertaken by assurors, readers have no way of assessing whether the assurance can then promote transparency and stakeholder accountability. In other words, readers have no way of knowing whether they can rely on the assurance statement in providing a clear and objective picture of the quality of the company's SES report (Ball et al. 2000). What value, then, would the assurance statement provide for the report's readers? 
Manurung\&Basuki-AnAnalyticalAssessmentofAssurancePracticesinSocialEnvironmentalan...

In a nutshell, since the percentage of assurors making reference to data review, systems and processes review, site visits, stakeholder interview and stakeholder engagement is significantly below 100 percent, it can be concluded that the rigor of work undertaken in the assurance process is not well portrayed in general.

\section{Information on Performance Dimension}

Both studies providing the basis for this research place importance in distinguishing the assessments of data accuracy and performance. It is important that assurors assess whether data in the report give a fair picture of reality (data accuracy), but it is even more important that they assess whether the company has done enough concerning their social responsibilities (performance). Stating that the data in the SES reports are accurate is not sufficient since this does not say whether the company has fulfilled all of its responsibilities towards its stakeholders. Ball et al. (2000) rightfully reveal that a valuable comment on performance is "arguably the most fundamental criterion for assuring an external constituency."

In this research, 36 percent of assurors make a reference to performance per se, compared to 15 percent observed by O'Dwyer and Owen and 13 percent by Ball et al. (2000) All 36 percent are consultants. An unparalleled example is Reassurance Network's assessment of Camelot's 2007 Responsibility Report. The consultant goes as far as stating how Camelot has performed according to each performance indicator.

Twenty eight showed positive movements, 12 were neutral and 16 showed a negative trend. There has been a marked positive movement in energy use, $\mathrm{CO}_{2}$ emissions, employee morale and sustainable paper sourcing... Most negative trends were not significant...Camelot should be commended for developing and consolidating its responsible business performance.

The last sentence of the example above shows that the consultant also measures the acceptability of Camelot's performance. Assurors must not only describe what companies have performed in order to fulfill their social responsibilities, but also examine whether these are acceptable. In other words, assurors must clearly state the bottom-line conclusion of their assessment of performance. Only $7(39 \%)$ of those assurors who assess performance state whether the performance is acceptable, which is quite an improvement from O'Dwyer and Owen's (2005) study, which finds that only one assuror makes such a statement.

Performance must also be assessed against something. In order to make performance assessment meaningful to stakeholders, performance must be assessed against stakeholder demands and preferably also against best practices. Of all the assurors who make a reference to performance, 50 percent assess performance against 
stakeholder demands and 39 percent against the best practice [compared to $11 \%$ in Ball et al.'s (2000) study]. For instance, Appendix D6 shows the assurance statement for GlaxoSmith Kline's 2007 Corporate Responsibility Report.

Interestingly, only half of the assurors that assess performance also clearly mention the weaknesses in performance, and only one of these assurors describes what the consequences of the weaknesses are. The rest either do not mention any weakness at all or briefly mention them in vague and broad wording. Deloitte and Touche, for example, mentions in its assessment of Vodafone's 2007 Corporate Responsibility Report that the company should improve in the future concerning "customer services management including customer complaints and satisfaction." No information is provided on the company's specific failings in its current customer services management.

Clear and specific recommendations concerning performance are also crucial for external constituencies to be able to judge a company's performance. 32 percent of assurors make recommendations concerning performance, nearly 90 percent of whom are consultants. Although this is an improvement from the percentage in Ball et al. (2000) in $2000(14 \%)$, very few of these recommendations are specific and clear. This is also parallel to the findings of the two previous studies.

The comparison of two recommendations is presented in Appendix
D7. The first is made by Reassurance Network's assessment of Camelot's 2007 Corporate Responsibility Report, and is decidedly clearer and more specific since it explains what the problem to be addressed is. The second is made by the same consultant for the same company, but in the previous year. It only mentions areas that need improvement, but not specifically what the problems in the areas are. Moreover, it explicitly states that the details on recommendations are available to management only. This shows a potentially managerialist approach where management may have the control over information to be publicly disclosed. Needless to say, this does not promote transparency and stakeholder accountability. Unfortunately, this is the approach taken by quite a number of assurors to providing recommendations.

On top of recommendations, assurors who have provided assurance for the same companies in the previous year(s) are also expected to provide feedbacks concerning how the companies have responded to their previous recommendations. It is logical to include such feedbacks in the assurance statement if the assuror truly aims to provide a clear and fair picture of the company's social performance. Of all the assurors who are not first-time assurors, 80 percent provide somekinds of feedbacks (compared to $29 \%$ in Ball et al. 2000). Feedbacks tend to be couched in fairly general terms, and assurors often fail to explain the extent to which the previous year's recommendations have been acted on. 
Manurung\&Basuki-AnAnalyticalAssessmentofAssurancePracticesinSocialEnvironmentalan...

A typical feedback is similar to the one provided by LRQA for its assessment on BT's 2007 Sustainability Report, "Recommendations made in assurance statements by LRQA for previous BT corporate social responsibility reports have been addressed." The feedback which was closest to be specific and detailed is the one provided by Camelot's assuror in 2008: "Camelot have achieved or partly achieved 28 of their 29 next step commitments made last year, and have responded to 11 of the 16 recommendations in our assurance statement." However, there is no mention of which recommendations have been and have not been addressed, or what "partly" means. The assuror also does not explain to what extent Camelot has successfully fulfilled the recommendations that they have responded to. This is the same as the findings of Ball et al. (2000), who label the feedback given as "opaque and broadly-termed."

\section{Information on Company Policies, Control Systems and Processes}

Besides assurance standards, stakeholder demands and the best practice, an assurance statement must also examine companies based on their own social responsibility policies. Ball et al. (2000) find that 18 percent of assurors make a reference to policy review, while this study observes 24 percent. In other words, only a miniscule improvement is observed. On the other hand, 64 percent claim to have re- viewed the control systems. In general, these assurors claim that the available systems and processes are adequate to ensure accurate reporting, but further improvement can be made. In fact, 78 percent of assurors make recommendations concerning the control systems.

Both the assessments and the recommendations made are again couched in broad terms. For example, BT's assuror in 2006 states that, "While some progress has been made, BT needs to develop further its guidance and processes that control the measurement and reporting of non-UK data." The general observation is that, despite the percentage of assurors making a reference to control systems [from $41 \%$ in Ball et al. (2000) and $39 \%$ in O'Dwyer and Owen (2005) to $64 \%$ in this study], the reference made has still not improved in clarity or details. Another interesting observation is that both Ball et al. (2000) and this study observe a curious phenomenon: the percentage of assurors making recommendations about the control systems is higher than that of assurors stating weaknesses in the control systems. In other words, some assurors see the room for improvement for the company's systems, but fail to specify what the weaknesses are. This does not help ensure stakeholders that assurors' best interests lie in the provision of a clear and just picture of the company.

Eighty six percent of assurors claim to have reviewed the processes 
taken by companies in creating their SES reports. This is a clear improvement from 22 percent in Ball et al.'s (2000) study. However, recommendations made about processes are again termed in broad and vague words. In general, assurors are likely to mention what needs to be improved, but not how it should be improved, which is arguably more important. An example of better recommendations can be seen in SGS U.K. Ltd.'s suggestions for GlaxoSmithKline in 2006 (Appendix D8).

\section{Information on Assurance Level}

In all sample observed, only 14 percent of assurors, all consultants, do not explicitly state the assurance level provided. These reports, which are the exception in this sample, simply do not offer any final opinion on the SES reports assessed. Shell's assurors in 2006, for example, simply state that, "The Company has prepared its 2006 Report with seriousness of purpose and openness to our questions and concerns."

The majority that do state the level of assurance provided, however, make it generally clear to readers. Accountants are especially so, stating whether "limited assurance" or "reasonable assurance" is pursued. These two levels of assurance are common among accountants. Several accountants provide limited assurance for certain aspects of the report and reasonable assurance for the rest. The general rationale for this is that they need to conduct more rigorous assurance methods or obtain more data in order to assure certain aspects of a report, and due to various constraints they are not able to do so. Hence, they are only able to apply limited assurance to these aspects. Again, this portrays accountants' general caution against putting too much liability on themselves, making their attestation less reassuring for report readers.

This can also be seen from the guarded and terse wording in their opinions. For example, PricewaterhouseCoopers states in their assurance statement for Anglo American's 2007 Report to Society that "...the KPIs selected for reasonable assurance for the year ended 31 December 2007 have been prepared, in all material respects, in accordance with corporate policies and procedures and are free from material misstatements." Most of the other accountants apply an opinion in very similar wording.

Consultants are generally more willing to apply a higher level of assurance. For example, Camelot's consultant assuror in 2007 explicitly states that a high level of assurance is pursued. CSR Network's assurance for Cooperative Group's 2008 Sustainability Report states an opinion that the report provides a "fair and balanced" view of the company's performance. For Traid Craft's 2008 Report, Just Assurance consultant states that, "On the basis of the work undertaken...we believe the Social Accounts properly describe Traid Craft's relationships with its stakeholders." 
Manurung\&Basuki-AnAnalyticalAssessmentofAssurancePracticesinSocialEnvironmentalan...

There are four aspects of assurance level that this study analyzes. The first is whether a "true and fair view" is used in stating the final opinion on the report. This approach, which is often used in financial audits, suggests "the completeness of the reporter's version of economic events" (Ball et al. 2000). The application of this opinion means that readers can rely on the SES report in order to form a balanced opinion on the company's performance. Although no assuror in this sample employs this approach - a phenomenon that is also observed in the two previous studies consultants are more likely to use opinions that use the term "fairness and balanced," which are words that accountants try to avoid in general. Accountants are more likely to limit their assurance to the properness of data, whereas consultants tend to go further and provide assurance for the company's performance as well. Needless to say, the approach taken by consultants in general is more reassuring.

The second aspect is whether the assuror provides an opinion on the accuracy of data. Besides two assurance statements for Shell's SES reports in 2007 and 2008, all other statements also provide this opinion. Indeed, data accuracy is what most accountants resolve to when it comes to providing an opinion, both in this paper and in the two previous studies.

The third aspect is whether the assuror provides an opinion on the reliability of the SES report. In other words, this is an opinion as to whether readers can rely on what the report says about the company. 54 percent of assurors do attest to the reliability of the report, with accountants (21\%) being less likely to do so than consultants $(77 \%)$. For example, Camelot's consultant assurors in 2008 state that, "We are satisfied that the content is representative of Camelot's performance throughout the reporting period and that there are no misrepresentations of data or performance."

The fourth aspect is whether the assuror provides an opinion on the balance of the report. In other words, this is an opinion on whether the report is a fair portrayal of reality by providing information about both the strengths and the weaknesses of the company's social responsibility performance. Only 18 percent of assurors, all of whom are consultants, make a clear reference to the balance of reporting. This echoes the results of the previous studies, which state that consultants in general are more likely to attest to a report's accuracy, reliability and balance, and therefore providing an opinion on the completeness of reporting.

Besides data accuracy, reliability and balance of report, there are three other aspects which must exist in a stakeholder-centered assurance statement. These are the important principles that govern the AA1000 Assurance Standard. They are covered in more details as follows.

- Materiality. The materiality principle demands assurors to state whether the report includes all performance-related information that 
is required by the company's stakeholders (AccountAbility 2003). 65 percent of assurors (compared to $32 \%$ in O'Dwyer and Owen's (2005) study) make a reference to materiality, but in broad wording. They do not explain what exactly they mean by materiality or what materiality levels have been set in their assurance engagement. A typical wording of this type of reference can be seen in the assurance statement accompanying BT's report in 2008. The statement says, "We are not aware of any material aspects concerning BT's sustainability performance that have been excluded from the report."

Also, although these assurors make a reference to materiality, their definition of materiality may not always be the same as that of the AA1000 Assurance Standard. A typical example is British American Tobacco's assurance statement for its SES report in 2007 (Appendix D9). Several things can be inferred from this statement:

- It is management, instead of stakeholder groups, who determines the material topics to be included in the report.

- Management makes this decision based on what is deemed important "to the readers of the report" and to the company's business. Stakeholder concerns are therefore not the main reference in determining the material topics to be covered by the report.
- The assuror can only attest that topics material to the company, as opposed to stakeholders, have not been left out from the report. As such, it is imaginable that not all stakeholder concerns might have been included in the report. As a result, the assuror has not fulfilled the AA1000 Assurance Standard's materiality definition.

Only 25 percent of assurors make a specific reference towards materiality that is based on stakeholder concerns. Although this is an increase from 5 percent figure observed in O'Dwyer and Owen's study in 2005, it is still a low percentage. An example is a statement made by CSR Network's assurance for Cooperative Group's 2008 Report, which asserts that, "We believe the report identifies the issues material to the Group's stakeholders...such that stakeholders are able to make informed judgments on the basis of its contents... Level of detail and transparency is to be commended." Another example is made by Enviros Consulting Ltd. in its assurance engagement with Thames Water Utilities in 2007. It declares that, "We are confident that Thames Water has thoroughly identified the issues of materiality to its stakeholders and tailored the report to best cover these issues." The remaining 10 percent of assurors do not make any reference to materiality at all. 
$\checkmark$ Completeness. The completeness principle set out by the AA1000 Assurance Standard requires assurors to analyze the extent to which the reporting company "can identify and understand material aspects of its sustainability performance"(AccountAbility 2003). The majority of assurors $(50 \%)$ make a reference to the issue of completeness, but do not provide specific details about the extent to which the reporting company can do what is required by the completeness principle. 40 percent make a reference that all information is provided to enable stakeholders to make informed judgments, which is four times as much as the figure observed in the O'Dwyer and Owen's (2005) study. The remaining 10 percent make no reference to completeness at all.

$\checkmark$ Responsiveness. Responsiveness principle in the AA1000 Assurance Standard states that assurors must evaluate whether the reporting company has "responded to stakeholder concerns, policies and relevant standards, and adequately communicated these responses in its report" (AccountAbility 2003). In order to do this, stakeholders must be engaged in the assurance process, and their opinions on the responsiveness of the reporting company must be asked. This inclusivity is indispensable in determining the extent of a company's responsiveness.
In the sample of this research, 64 percent of assurors make no reference to the company's responsiveness. The remaining 36 percent (compared to $29 \%$ from Ball et al.'s (2000) study) include a specific reference that explains the extent to which the reporting company has responded to stakeholders and reported about this. The assurance statement companying Camelot's 2008 Report is again a good example for this. It elaborates on the stakeholder dialogues, surveys and forums used by Camelot in acquiring and understanding stakeholder inputs and concerns. It states clearly that Camelot's responses to stakeholders are deemed good against the best practice, and that processes to ensure responsiveness to stakeholders are "well-embedded" in the company. In conclusion, it asserts that Camelot has "demonstrated a high level of responsiveness to issues raised by stakeholders across all areas of business." A detailed example can be seen from Just Assurance's assessment of Traid Craft's 2008 Social Accounts (Appendix D10).

The low portion of assurors making a specific reference to responsiveness is parallel to the low portion of assurors claiming to have involved stakeholders in the assurance process. This result is similar to those of the previous two studies. 
Gadjah Mada InternationalJournal of Business,January-April 2010, Vol. 12,No. 1

\section{The Scope and Limitations of the Research}

This research is based on a combination of studies conducted by Ball et al. (2000) and O'Dwyer and Owen (2005). As further elaborated in part two, these studies share the same research purpose as this paper. However, we combine the key questions fromboth studies (there are some variations), and apply them to this paper. This paper also extends and updates those studies in the sense that we use the same type of data but from a more recent period (2006-2009). Ball et al. (2000) used the data from the period of 1991-1998 while O'Dwyer and Owen (2005) used the data from 2002. Furthermore, we expand the scope of this study to also cover companies in North America, as opposed to just British companies as those two studies did.

The scope of this study covers assurance statements accompanying non-financial corporate reports produced by British and North American companies and short-listed for the ACCA U.K. and ACCA-CERES Sustainability Reporting Awards from 2006 to 2008. The study then has a distinct British and North American contexts, and its findings may not be directly translatable to similar assurance practices in other countries. The study of Chua et al. (2009) supports this view since it finds that the assurance practice has country-specific factors. Moreover, the data used are also limited to a particular sample from a particular time period. This should be kept in mind when viewing the results of this study.

The research methods, also introduce further limitations to this study. Since this study deduces assurance levels only based on whatever assurance statements are published publicly, its approach is inherently subjective. A content analysis of assurance statements allows us to infer about the processes behind the assurance to a certain extent, but in-depth case studies involving auditors performing an assurance engagement would allow moreinsights. Thus, although the analysis is done with utmost thoroughness and care, my own value judgments cannot be separated from the analysis. However, the findings of this study can still present a valuable and noteworthy starting point towards understanding the current practices of non-financial audits in the United Kingdom and North America, the same way that the studies of Ball et al. (2000) and O'Dwyer and Owen (2005) have provided scholars in the field a valuable insight into a similar topic.

\section{Summary and Conclusion}

The objective of this study is to continue and extend the studies of Ball et al. (2000) and O'Dwyer and Owen (2005) in evaluating the extent to which current assurance practices promote transparency and accountability to stakeholders. This is carried out by conducting an empirical analysis of the content of assurance statements accompanying a sample of non-financial 
Manurung\&Basuki-AnAnalyticalAssessmentofAssurancePracticesinSocialEnvironmentalan...

reports short-listed for the Association of Chartered Certified Accountants (ACCA) U.K. Sustainability Reporting Award and the CERES-ACCA Sustainability Reporting Award from 2006 to 2008. To guide the empirical analysis, the principles of materiality, completeness and responsiveness embedded in several recent assurance standards are utilized. These include AccountAbility's AA1000 Assurance Standard, an assurance guide released by the Federation des Experts Comptables Europeens and Global Reporting Initiative's G3 guidelines; nevertheless, the first standard is the main criteria used. Besides these principles, this study is also concerned about several other types of information provided in the assurance statements, namely information on the assurance provider, the intended readership, the assuror independence, the assurance processes and methods, the performance dimension, the company policies and control systems and processes, and the assurance level. All this information can provide valuable insights into the transparency and stakeholder accountability of social, environmental and sustainability reporting.

Based on the sample of this research, several new trends in social, environmental and sustainability assurance can be observed. The first is that accountants tend to limit their intended readership to management only and state a disclaimer for other potential readers. This diminishes the transparency and stakeholder accountability of the reporting. It also raises doubts about the assuror independence since the assuror is supposed to assess the work of the company and report the assessment results to the company as well. In several cases, the assuror even has to assess the company's work based on the company policies and procedures instead of stakeholder concerns and perspectives. As such, this is even a more extreme example of assurance being a spun off managerial practice, as observed by Ball et al. (2000) in their own research in 2000 . Concerning consultants, they tend not to address specific constituencies, which also raises doubts about the extent to which the assurance process is stakeholder-centered. The omission of stakeholder involvement in the assurance process may result in not all stakeholder concerns being taken into consideration. In a nutshell, both the approaches of the accountants and the consultants reduce the value that the assurance statement can add to the company reporting.

The second trend is that there is even stronger evidence that management has a control over the scope of the assurance engagement and over what information gets publicly disclosed. The evidence is shown in the fact that in many assurance statements prepared by accountants, only selected parts of the reports are being assured, with no indication that it is not management who selects these parts. Other evidence is the fact that detailed recommendations about the company's performance are often reserved for management only, and the assurance 
statement only vaguely lists what areas of the company's performance need improvements. This is also evident in the fact that quite a number of reports are being assessed mainly based on company policies and procedures.

All these have implications on the assuror independence. Although most assurors declare their independence from the reporting company and ensure that they do not have other relationships with the company that could impair their objectivity, they still seem to be appointed by the management instead of the stakeholders. Moreover, as mentioned before, the accountant assurors often limit their responsibilities to management only. As a result, they cannot be said to be fully independent in spite of their independent declaration. Less-than-full independence, as also observed by the two previous studies, can result in the lack of valueadding attestation elements, and in the sample of this research, this too has been observed. More details about this are provided below. Consultants in general appear to be more independent, with only two cases of dissociated consultancy.

When it comes to assuror information, the percentage of assurors providing full information on their fee levels, responsibilities, competencies, backgrounds and past experiences is still significantly below 100 percent. In relative terms, there is not much improvement from the previous two studies, although several consultants obviously put great efforts in trying to comply with the prevalent assurance standards concerning the provision of assuror information. In absolute terms, plenty of improvement and transparency is still needed in this area. There is a significant improvement, compared to the two previous studies, in terms of the provision of information on assurance scope and criteria used. However, the sample of this study does not show a significant increase in the percentage of assurors conducting the assurance methods more rigorously. In other words, the robustness of the assurance methods has not improved much. This cripples the report readers' abilities in judging how the assurors come to their conclusion about the company's performance and reporting.

Only consultants in general make an improvement in assessing and making a reference to the company's social, environmental and sustainability performance. Accountants fail greatly in this regard by not making any reference to performance per se and by focusing mainly on data accuracy, control systems and processes. This shows that accountants generally avoid conducting a first-order audit. Several consultants attempt to be more extensive in their performance assessment by assessing the acceptability of performance, gauging the performance against stakeholder demands and the best practice, and providing the explanations of performance weaknesses and recommendations for improvement. However, their wording tends to be opaque and broad, with only a few consultants attempting to go beyond 
Manurung\&Basuki-AnAnalyticalAssessmentofAssurancePracticesinSocialEnvironmentalan...

that. Thus, it can be said that the percentage of assurors assessing various aspects of performance has increased, but the quality of the assessment itself has not necessarily improved. The same can be said about the reviews of company policies, systems and processes, and also of feedbacks provided by assurors concerning the extent to which the company has responded to previous years' recommendations. This may result from the lack of robustness of assurance methodology, which diminishes the assurors' abilities to come to an informed opinion on the reporting company's performance. Thus, in a nutshell, the rigor of the work undertaken is still far from sufficient, and this reduces the value of the assurance statements even further.

Similar to the results of the two previous studies, consultants are more likely to provide a higher level of assurance, which is more valuable and reassuring for report readers. They are more likely to go into the details of the accuracy, reliability and balance of the report, and of the completeness of reporting. Accountants are mainly focused on the accuracy of data, refraining from expressing an opinion on the extent to which the company reports are reliable and balanced. Compared to the previous studies, more consultants in this sample explicitly or implicitly state that a high level of assurance is pursued. This difference in approach can also be seen from the differences in wording used by the two professions. While accountants use restric- tive and terse vocabularies, consultants are more likely to use positive terms.

Another interesting trend is that more and more assurors are trying to comply with the AA1000 Assurance Standard's principles of materiality, completeness and responsiveness, but failing greatly in their attempts. Most of the assurors observed in this sample mention explicitly that they intend to focus on these three principles in their assurance statements. However, they fail since they do not apply the definitions in the AA1000 Assurance Standard. For instance, they state that they have assessed the materiality of the company report, but based on the company's own policies and procedures, whereas the Standard requires them to base their assessments on the stakeholder demands. In other words, similar to the issue of performance assessment, the percentage of assurors attempting to measure the materiality, completeness and responsiveness has increased, but the quality of the measurement is still low.

Stakeholder engagement or inclusivity, which is the center of the AA1000 Assurance Standard that is predominantly used by the assurors in this sample, is still minimal. Similar to the cases above, more and more assurors are trying to provide more proofs of stakeholder involvement in their assurance process. However, they do not provide enough details about what types of stakeholder involvement activities are conducted, what types of stakeholders are involved, what they 
do during these activities and what feedbacks they receive from the stakeholders. As such, the information provided is simply empty information that does not add any value to the reliability of the reporting. This cannot be expected to increase the readers' confidence in the report and the accompanying assurance statements.

The bottom line conclusion of this study is clear. Perhaps due to the increasing critiques directed at the assurance process and the increasing pressure for companies to comply with the prevalent assurance standards, more and more assurors are attempting to include the principles of these standards in their assurance engagements. However, while the quantity of these attempts has increased, the sample of this study shows that the quality has not. By reading the fine prints of assurance statements, much can be inferred that points to the lack of rigor, transparency and stakeholder accountability in the assurance process. In other words, the recent practices of assurance en- gagements represented by the sample in this study have not improved the transparency and stakeholder accountability of social, environmental and sustainable reporting. Similar to the two previous studies, we assert that a generally accepted standard is needed to promote assurance statements that add meaningful values to the reliability of social, environmental and sustainability reporting.

It should be kept in mind that the conclusion of this study is derived from a specific sample which is confined to publicly disclosed assurancestatements only. The methods of this study, albeit comprehensive, also rely on a content analysis of the sample. Thus, the value judgment cannot fully be separated from the observations of this study. In order to eliminate these limitations, further studies should attempt to conduct a case study following real assurance engagements in order to gain a deeper insight into the relationships between assurors and management and the rigor of the assurance process.

\section{References}

AcountAbility. 1999. AA1000 Framework: Standard, Guidelines and Professional Qualification. London: AccountAbility.

AccountAbility. 2003. AA1000 Assurance Standard. London: AccountAbility.

Adams, C. A. 2004. The ethical, social and environmental reporting performance portrayal gap. Accounting, Auditing and Accountability Journal 17 (5): 731-57.

Ball, A., D. L. Owen, and R. H. Gray. 2000. External transparency or internal capture? The role of third party statements in adding value to corporate environmental reports. Business Strategy and the Environment 9 (1): 1-23. 
Manurung\&Basuki-AnAnalyticalAssessmentofAssurancePracticesinSocialEnvironmentalan...

Belal, A. R. 2002. Stakeholder accountability or stakeholder management: A review of UK firms' social and ethical accounting, auditing and reporting (SEAAR) practices. Corporate Social Responsibility and Environmental Management 9: 8-25.

Brorson, T., and J. Park. 2004. Experiences and views on third-party assurance of corporate environmental and sustainability reports. Journal of Cleaner Production 13: 10951106.

Chua, W. F., R. Simnett, and A. Vanstraelen. 2009. Assurance on sustainability reports: An international comparison. The Accounting Review 84 (3): 937-967.

Dando, N., and T. Swift 2003. Transparency and assurance: Minding the credibility gap. Journal of Business Ethics 44(2): 195-200.

FEE (Federation des Experts Comptables Europeens). 2002. Providing Assurance on Sustainability Reports. Brussels: FEE.

GRI(Global Reporting Initiative). 2002. Sustainability Reporting Guidelines on Economic, Environmental and Social Performance. Amsterdam: GRI.

KPMG. 2008. KPMG International Survey of Corporate Responsibility Reporting 2008. Amsterdam: KPMG Global Sustainability Services.

O’Dwyer, B., and D. Owen. 2005. Assurance statement practicein environmental, social and sustainability reporting: A critical evaluation. British Accounting Review 37 (2): 20529.

O’Dwyer, B., and D. Owen. 2007. Seeking stakeholder-centric sustainability assurance. Journal of Corporate Citizenship 25: 77-94.

Power, M. 1991. Auditing and environmental expertise: Between protest and professionalization. Accounting, Auditing and Accountability Journal 4 (3): 30-42.

Maltby, J. 1995. Environmental audit: Theory and practices. Managerial Auditing Journal 10(8): 15-26.

Steckel, C. 2002. The ACCA UK Awards for sustainability rewarding 2001. www.accaglobal.com/students/student accountant/archive/2002 (Retrieved May 2009)

Zadek, S. 2004. Charting the future of sustainability assurance. Business and the Environment. 
APPENDIX A. Companies Short-Listed for the ACCA UK Sustainability Reporting Awards

\begin{tabular}{|c|c|c|}
\hline $\begin{array}{l}\text { The First Year: } \\
2006\end{array}$ & $\begin{array}{l}\text { The Second Year: } \\
2007\end{array}$ & $\begin{array}{l}\text { The Third Year: } \\
2008\end{array}$ \\
\hline Anglo American & Anglo American & Anglo American \\
\hline BHP Billiton & BHP Billiton & $\begin{array}{l}\text { British American } \\
\text { Tobacco Plc }\end{array}$ \\
\hline BP Plc & BP Plc & BHP Billiton \\
\hline BT Group Plc & BT Group Plc & BP Plc \\
\hline $\begin{array}{l}\text { Co-operative Financial } \\
\text { Services }\end{array}$ & Camelot & BT Group Plc \\
\hline Centrica Plc & GlaxoSmithKline & Camelot Group Plc \\
\hline $\begin{array}{l}\text { Guardian Newspaper } \\
\text { Limited }\end{array}$ & $\begin{array}{l}\text { Island Water Services } \\
(\mathrm{SME})\end{array}$ & GlaxoSmithKline \\
\hline Shell International Limited & Shared Interest (SME) & REAP \\
\hline $\begin{array}{l}\text { Thames Water Utilities } \\
\text { Limited }\end{array}$ & Shell International BV & Royal Dutch Shell Plc \\
\hline Vodafone & $\begin{array}{l}\text { Thames Water Utilities } \\
\text { Ltd }\end{array}$ & $\begin{array}{l}\text { The Cooperative } \\
\text { Group }\end{array}$ \\
\hline Xstrata & $\begin{array}{l}\text { The Body Shop } \\
\text { International }\end{array}$ & Traid Craft \\
\hline FRC Group (SME) & Traid Craft (SME) & Unilever \\
\hline $\begin{array}{l}\text { Share Interest } \\
\text { Society Ltd (SME) }\end{array}$ & Unilever & Vodafone Group Plc \\
\hline Traid Craft (SME) & Vodafone & Xstrata Plc \\
\hline $\begin{array}{l}\text { Workspace Group } \\
\text { Plc (SME) }\end{array}$ & Xstrata Plc & \\
\hline
\end{tabular}

108 
Manurung\&Basuki-AnAnalyticalAssessmentofAssurancePracticesinSocialEnvironmentalan...

APPENDIX B. Companies Short-Listed for the CERES-ACCA Sustainability Reporting Awards

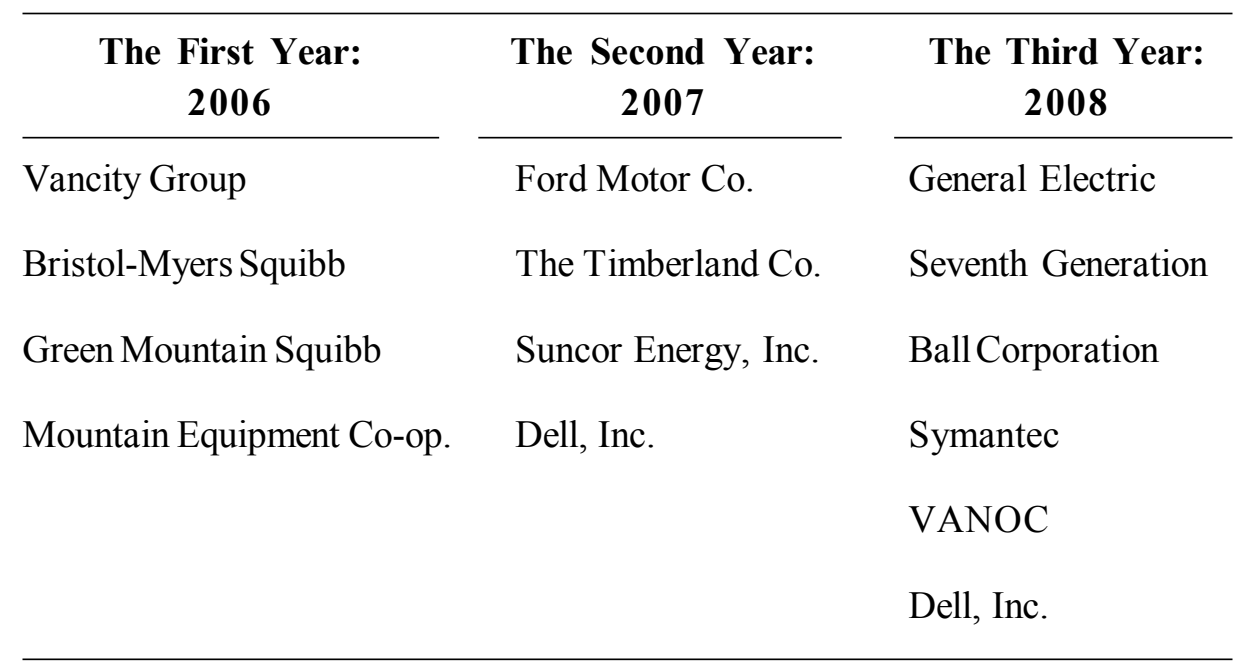


Gadjah Mada InternationalJournal of Business,January-April 2010,Vol. 12,No. 1

\section{APPENDIX C}

The key questions guiding this study are a combination of the key questions guiding Ball et al. (2000) and O'Dwyer and Owen (2005). Hence, they are more comprehensive than the questions posed in this study. The questions are as follows:

\section{Information on Assurance Provider:}

- Does the SES report have a third-party assurance statement?

- What is the profession of the assuror?

- Is there an indication of fee levels for the service provided?

- Is the type of statement stated?

- Are the responsibilities of assuror and reporter clearly laid out?

- Are the assuror's competencies, background and past experience in the assurance service provision clearly described?

\section{Information on Intended Readership:}

- Does the assurance statement clearly address specific stakeholder groups as their intended readers?

- Are the addressed stakeholder groups the same as those addressed by the SES report that is verified by the assurance statement?

\section{Information on Assuror Independence:}

- Does the assuror appear to be independent of the corporate management?

- Does it provide other services to or engage in business deals with management, whether currently or in the past?

- Is the degree of assuror independence made clear in the statement?

- Does the assuror recognize the implication of less-than-full independence from the reporting company?

\section{Information on Assurance Process and Methods:}

- Is the assurance scope, criteria and standards used clearly explained?

- Which standards are they?

- Is it mentioned clearly and in details whether only parts of the standards are used in the assurance process?

- Does the assuror clearly describe the work undertaken in the assurance?

- Are data provided in the SES report validated in any way? 
Manurung\&Basuki-AnAnalyticalAssessmentofAssurancePracticesinSocialEnvironmentalan...

- Is data review undertaken?

- Is management control systems review undertaken?

- Are site visits undertaken?

- Are interviews with company stakeholders undertaken?

- To what extent is stakeholder engaged in the assurance process?

- Are restrictions on this clearly described?

\section{Information on Performance Dimension:}

- Is there any reference to performance per se?

- Is there any reference to performance in terms of what is required by stakeholders?

- Is the company's performance assessed against best practice?

- Is there any reference to acceptability of performance?

- How is the wording of the report concerning the four previous questions?

- Are weaknesses in performance clearly identified?

- Is there a discrepancy between a perceived weakness in performance and a perceived weakness in the management control system?

- Are risks or consequences associated with the identified risks mentioned?

- Are concrete recommendations made?

- How is the wording of the weaknesses and recommendations?

- Is there feedback about how the company has improved against last year's recommendations, if any?

- How is the wording of the feedback?

- Does the assuror clearly and in concrete terms mention what kind of progress is expected from the company?

\section{Information on Company Policies and Control Systems:}

- Is the company's environmental policy assessed and the result clearly explained?

- Does the assuror link the attestation to the company policy?

- Are the underlying processes, systems and reporting procedures assessed?

- Are weaknesses and recommendations in this area clearly stated?

- How is the wording of the weaknesses and recommendations? 


\section{Information on Assurance Level:}

- Is the level of assurance provided?

- Does the assuror use the phrase 'true and fair view'?

- In what form are opinions stated?

- Do conclusions reached on the report address issues such as accuracy, completeness, reliability and balance as called for in the GRI guidance?

- To what extent do statements address the core assurance principles of materiality, completeness and responsiveness emphasized in AccountAbility's AA1000 assurance standard? 


\section{APPENDIX D}

\section{Appendix D1}

A typical example is shown by Ernst and Young's assurance for British American Tobacco's 2002 Sustainability Report.

Our responsibility in performing our assurance activities is to the management of British American Tobacco plc only and in accordance with the terms of reference agreed with them. We do not therefore accept or assume any responsibility for any other purpose or to any other person or organization.

\section{Appendix D2}

For example, Ernst and Young states the following in their assurance statement for British Petroleum's 2007 Sustainability Report:

We confirm annually with BP whether there have been any events including the provision of prohibited services that could impair our independence or objectivity. There were no such events or services in 2007.

\section{Appendix D3}

This term refers to a situation where :

the third-party statement writer is clear that a consultancy relationship exists with the reporter. However, the verification statement leaves the reader with the sense that the verifier has temporarily cut him/herself off from this association in order to express an opinion on the report more independently than the degree of intertwining implies (Ball et al.2000).

\section{Appendix D4}

In one case (Reassurance Network's verification for Camelot's 2007 Corporate Responsibility Report), the assuror clearly states that,

Our role... has been to recommend amendments where we felt information was insufficiently accurate, may have been misleading or was incomplete. Under our agreement with Camelot, any subsequent changes to the web-based Report will be notified to the Reassurance Network and will be subject to verification and assurance before publication. 
Gadjah Mada InternationalJournal of Business, January-April 2010,Vol. 12,No. 1

\section{Appendix D5}

Data review and validation seems like the most obvious task that needs to be carried out in an assurance engagement, only 86 percent of assurors make clear reference to this. Those that do not include the assurors for Shell's Sustainability Reports, which simply explain their assurance method as follows:

In autumn 2007, we commented on Shell's initial choice of issues to address in the report. We reviewed and commented on the Report outline in late 2007, and successive report drafts in January and March 2008... Our in-person meetings involved interviews with senior management, including the Chief Executive and the Board's Social Responsibility Committee.

\section{Appendix D6}

For example, Bureau Veritas states in its assurance statement for GlaxoSmithKline's 2007 Corporate Responsibility Report that,

Feedback from stakeholders indicates that GSK is performing well in relation to vaccines; differential pricing; PPPs, R\&D; and the Accelerating Access Initiative which illustrates a partnership approach to healthcare and provides information on direct impacts.

\section{Appendix D7}

Comparison of two recommendations:

There is a need to monitor the effectiveness of important communications - despite major improvements, there are still some examples of communications not being received. Monitoring and measurement of reach and understanding on all key communications is important and currently missing.

(Reassurance Network's assessment of Camelot's 2007 Corporate Responsibility Report)

We have made a number of detailed recommendations for further improvement in a confidential report to management and the external Advisory Panel for Social Responsibility...It includes the following areas: Continued progress in employee management, communication and the integration of corporate responsibility; Developments in environmental management, including the recycle of Point-of-Sale materials; Better use of informal channels for dialogue with external stakeholders; A broadening of the management of responsible practices within Camelot's supply chain.

(Reassurance Network's assessment of Camelot's 2006 Corporate Responsibility Report)

Notes: The first one is made by Reassurance Network's assessment of Camelot's 2007 Corporate Responsibility Report and is decidedly clearer and more specific, since it explains what the problem to be addressed is. The second one is made by the same consultant for the same company, but in the previous year. 
Manurung\&Basuki-AnAnalytical AssessmentofAssurancePracticesinSocialEnvironmentalan...

\section{Appendix D8}

An example of better recommendations can be seen in SGS U.K. Ltd.'s suggestions for GlaxoSmithKline in 2006, which state that the company should:

Consider incorporation of an internal audit of data and data management systems alongside corporate EHS audits; Ensure training is undertaken when key individuals are replaced to ensure consistency and full understanding of systems and requirements; Ensure that, when sites submit data, comments are included to explain estimations, calculations and any significant changes.

\section{Appendix D9}

A typical example is British American Tobacco's assurance statement for its SES report in 2007. It is stated that,

The application of materiality process has required a significant degree of judgment by management on the relevance of particular topics to the readers of the Report and the significance to British American Tobacco's business. We are not aware of any key topics considered most material by British American Tobacco through this process that were not included in the Report.

\section{Appendix D10}

A detailed example of the assessment of the company's responsiveness towards its staff (Just Assurance's assessment of Traid Craft's 2008 Social Accounts):

We found that concerns staff had identified in previous staff surveys regarding the way some new HR policies were introduced have been addressed and that while some scores in the 2007/8 staff surveywere lower, we accept the validity of the explanations in the commentary. Some issues staff had have been addressed through a comprehensive and on-going 'Rights and Responsibilities' training program for all staff. This has had real benefits for staffin improving their work environment and resolving sometimes long standing problems. We recognize the strong, developing role of the Traid Craft Staff Association in supporting the staff as a whole and in counseling individuals. 